\title{
PENGARUH CELEBRITY ENDORSER, TAGLINE DAN CITRA MEREK TERHADAP KESADARAN MEREK KONSUMEN FACIAL FOAM POND'S DI SMK AL-MAKMUR CIGANJUR JAKARTA SELATAN
}

\section{Putri Oktaviani Rahayu Lestari}

Email : puuutrioktaviani@gmail.com, rahayulestari22@yahoo.com

Program Studi Manajemen Fakultas Ekonomi

Universitas Nasional

\begin{abstract}
ABSTRAK
Penelitian ini bertujuan untuk menguji dan menganalisis pengaruh celebrity endorser, tagline dan citra merek terhadap kesadaran merek konsumen facial foam Pond's di SMK Al-Makmur Ciganjur, Jakarta Selatan. Populasi dalam penelitian ini adalah siswa-siswi dan karyawan di SMK Al-Makmur Ciganjur, Jakarta Selatan yang menggunakan facial foam Pond's. Jumlah sampel yang digunakan dalam penelitian ini adalah 100 responden. Metode yang digunakan dalam penelitian ini adalah regresi linear berganda. Hasil penelitian menunjukkan bahwa celebrity endorser, tagline dan citra merek secara parsial berpengaruh positif dan signifikan terhadap kesadaran merek pada konsumen facial foam Pond's di SMK Al-Makmur Ciganjur, Jakarta Selatan.
\end{abstract}

Kata kunci: Celebrity endorser, tagline, citra merek, kesadaran merek

\section{ABSTRACT}

This study aims to test and analyze the effect of celebrity endorser, tagline, and brand image on brand awareness of Pond's facial foam consumers at SMK Al-Makmur Ciganjur, South Jakarta. The method used in this study is multiple linear regression. Population that used in this study is students and empolyees at SMK Al-Makmur Ciganjur, South Jakarta who use Pond's facial foam. The amount of samples used in this study is 100 respondents. Result of the study shows that celebrity endorser, tagline and brand image partially has positive and significant effect on brand awareness of Pond's facial foam consumers at SMK Al-Makmur Ciganjur, Jakarta Selatan.

Keywords: Celebrity endorser, tagline, brand image, brand awareness

\section{PENDAHULUAN}

Penampilan merupakan hal yang penting bagi masyarakat modern. Penampilan menarik merupakan tuntutan yang dapat menunjang kepercayaan diri seseorang. Oleh karena itu, banyak kaum wanita yang terobsesi untuk tampil menarik seperti artis. Hal ini menimbulkan perkembangan pesat pada bisnis produk perawatan dan kecantikan. Beragam merek produk perawatan dan kecantikan bermunculan guna memenuhi kebutuhan masyarakat terhadap produk-produk tersebut.

Keragaman merek menyebabkan terjadinya persaingan yang ketat dalam industri kecantikan dan perawatan kulit wajah. Agar mampu bertahan dan berkembang di tengah 
persaingan usaha dalam jangka panjang, berbagai macam strategi pemasaran dilakukan oleh perusahaan untuk menarik perhatian dan minat konsumen terhadap barang yang diproduksinya.

Kesadaran terhadap suatu merek (brand awareness) merupakan hal yang penting dalam pemasaran suatu produk. Menurut Aaker (1997) dalam Rangkuti (2004:39), kesadaran merek adalah kesanggupan seorang calon pembeli untuk mengenali atau mengingat kembali bahwa suatu merek merupakan bagian kategori produk tertentu. Kesadaran merek menunjukkan tingkat kemampuan suatu produk untuk dikenali dan diingat kembali oleh konsumen. Kesadaran merek dapat mempengaruhi kinerja penjualan suatu perusahaan. Tingginya tingkat kesadaran terhadap suatu merek dapat mencerminkan tingginya keputusan pembelian terhadap merek tersebut. Oleh karena itu, tingginya tingkat kesadaran terhadap suatu merek yang diproduksi oleh perusahaan dapat menentukan kemampuan perusahaan tersebut untuk bertahan dan berkembang di tengah ketatnya persaingan.

Kesadaran merek dapat dipengaruhi oleh beberapa faktor. Salah satu faktor yang dapat mempengaruhi kesadaran merek adalah celebrity endorser. Shimp (2003:460) menyatakan bahwa celebrity endorser adalah suatu bentuk promosi yang menggunakan artis sebagai bintang iklan di media-media, mulai dari media cetak, media sosial, maupun media televisi. Hasil penelitian yang dilakukan oleh Hamid dan Hartati (2013) dan Nugroho dan Mudiantono (2013) menunjukkan bahwa celebrity endorser berpengaruh positif dan signifikan terhadap kesadaran merek. Hal tersebut menunjukkan bahwa semakin efektif penggunaan celebrity endorser dalam kegiatan promosi suatu merek, maka semakin tinggi tingkat kesadaran masyarakat terhadap merek tersebut.

Tagline juga dapat mempengaruhi kesadaran merek. Hasil penelitian yang dilakukan oleh Abiromo (2014) menunjukkan bahwa tagline bepengaruh positif dan signifikan terhadap kesadaran merek. Hal tersebut dikarenakan semakin bagus tagline suatu merek, maka semakin mudah konsumen dalam mengerti dan memahami suatu merek, sehingga semakin tinggi daya tarik dan kesadaran masyarakat terhadap merek tersebut.

Faktor lain yang dapat mempengaruhi kesadaran merek adalah citra dari suatu merek. Hasil penelitian yang dilakukan oleh Bramantya dan Jatra (2016) menunjukkan bahwa citra merek berpengaruh positif dan signifikan terhadap keputusan pembelian. Adapun hasil penelitian yang dilakukan oleh Yanti dan Sukotjo (2016) menunjukkan bahwa citra merek dan kesadaran merek berpengaruh positif dan signifikan terhadap keputusan pembelian. Hal tersebut menunjukkan adanya keterkaitan antara citra merek dan kesadaran merek. Semakin 
baik citra yang digambarkan atas suatu merek, maka merek tersebut semakin menarik bagi masyarakat, sehingga semakin tinggi tingkat kesadaran masyarakat terhadap merek tersebut.

Tabel 1. Top Brand Index Facial Foam Tahun 2015-2016

\begin{tabular}{|c|c|c|c|c|c|}
\hline Tahun 2015 & \multirow{2}{*}{$\begin{array}{c}\text { Top } \\
\text { Brand } \\
\text { Index }\end{array}$} & \multirow[b]{2}{*}{ Predikat } & Tahun 2016 & \multirow{2}{*}{$\begin{array}{c}\text { Top } \\
\text { Brand } \\
\text { Index }\end{array}$} & \multirow[b]{2}{*}{ Predikat } \\
\hline Merek & & & Merek & & \\
\hline Pond's & $39.4 \%$ & TOP & Pond's & $40.6 \%$ & TOP \\
\hline Biore & $23.3 \%$ & TOP & Biore & $21.2 \%$ & TOP \\
\hline Papaya (RDL) & $5.6 \%$ & - & Garnier & $9.1 \%$ & - \\
\hline Garnier & $5.3 \%$ & - & Papaya (RDL) & $5.3 \%$ & - \\
\hline Nivea & $2.3 \%$ & - & & & - \\
\hline
\end{tabular}

(Sumber: Top Brand Award, 2016)

Berdasarkan tabel atas, dapat diketahui bahwa Pond's selalu menduduki posisi pertama dalam top brand index produk facial foam di Indonesia selama dua tahun terakhir. Hal tersebut dapat mencerminkan bahwa tingkat kesadaran terhadap merek facial foam Pond's lebih tinggi daripada tingkat kesadaran terhadap merek facial foam lainnya. Hal ini merupakan capaian yang baik bagi Pond's. Oleh karena itu, Pond's perlu mempertahankan dan meningkatkan kesadaran konsumen terhadap mereknya agar dapat terus memenangkan persaingan di industri perawatan kulit wajah di Indonesia yang semakin ketat.

Berdasarkan latar belakang tersebut, perlu dilakukan penelitian untuk menguji dan menganalisis pengaruh celebrity endorser, tagline dan citra merek terhadap kesadaran merek facial foam Pond's.

\section{TINJAUAN PUSTAKA}

\section{Celebrity Endorser}

Penggunaan narasumber (source) sebagai figur penarik perhatian dalam iklan merupakan salah satu cara kreatif untuk menyampaikan pesan (Kotler dan Keller, 2009). Pesan yang disampaikan oleh narasumber yang menarik akan lebih mudah dan menarik perhatian konsumen. Narasumber yang digunakan dalam iklan disebut endorser. Menurut Shimp (2007:460), endorser adalah pendukung iklan atau yang dikenal juga sebagai bintang iklan dalam mendukung iklan suatu produk.

\section{Tagline}

Menurut Nuradi, dkk (1996:56), tagline adalah kalimat singkat sebagai penutup teks inti dari iklan yang menyimpulkan secara singkat tujuan komunikasi dari iklan itu sendiri. Tagline dapat digunakan untuk membantu mengomunikasikan titik pembeda dari pesaing (Susanto dan Wijanarko, 2004:86). 


\section{Citra Merek}

Menurut Keller (2003:166), citra merek (brand image) adalah anggapan tentang merek yang direfleksikan konsumen yang berpegang pada ingatan konsumen dan cara orang berpikir tentang sebuah merek secara abstrak dalam pemikiranmereka, sekalipun pada saat mereka memikirkannya, mereka tidak berhadapan langsung dengan produk.

\section{Kesadaran Merek}

Menurut Aaker (1997) dalam Rangkuti (2004:39), kesadaran merek adalah kesanggupan seorang calon pembeli untuk mengenali atau mengingat kembali bahwa suatu merek merupakan bagian kategori produk tertentu. Peter dan Olson (2013) menyatakan bahwa kesadaran merek merupakan sebuah tujuan umum komunikasi untuk semua strategi promosi.

\section{Keterkaitan Antarvariabel}

\section{Keterkaitan antara Celebrity Endorser dan Kesadaran Merek}

Shimp (2003:460) menyatakan bahwa celebrity endorser adalah suatu bentuk promosi yang menggunakan artis sebagai bintang iklan di media-media, mulai dari media cetak, media sosial, maupun media televisi. Celebrity endorser diharapkan dapat meningkatkan daya tarik terhadap suatu merek, sehingga pada akhirnya dapat meningkatkan kesadaran terhadap merek itu sendiri. Hal tersebut menunjukkan bahwa celebrity endorser memiliki pengaruh yang positif terhadap kesadaran merek. Semakin baik penggunaan celebrity endorser dalam suatu merek, maka semakin tinggi daya tarik dan tingkat kesadaran masyarakat terhadap merek tersebut. Hal ini sesuai dengan hasil penelitian yang dilakukan oleh Hamid dan Hartati (2013) dan Nugroho dan Mudiantono (2013) yang menunjukkan bahwa celebrity endorser berpengaruh positif dan signifikan terhadap kesadaran merek.

$\mathrm{H}_{1}$ : Celebrity endorser berpengaruh positif dan signifikan terhadap kesadaran merek facial foam Pond's di SMK Al-Makmur Ciganjur, Jakarta Selatan.

\section{Keterkaitan antara Tagline dan Kesadaran Merek}

Hasil penelitian yang dilakukan oleh Abiromo (2014) menunjukkan bahwa tagline bepengaruh positif dan signifikan terhadap kesadaran merek. Hal tersebut dikarenakan semakin bagus tagline suatu merek, maka semakin mudah konsumen dalam mengerti dan 
memahami suatu merek, sehingga semakin meningkatkan daya tarik dan kesadaran masyarakat terhadap merek tersebut.

$\mathrm{H}_{2}$ : Tagline berpengaruh positif dan signifikan terhadap kesadaran merek facial foam Pond's di SMK Al-Makmur Ciganjur, Jakarta Selatan.

\section{Keterkaitan antara Citra Merek dan Kesadaran Merek}

Hasil penelitian yang dilakukan oleh Bramantya dan Jatra (2016) menunjukkan bahwa citra merek berpengaruh positif dan signifikan terhadap keputusan pembelian. Adapun hasil penelitian yang dilakukan oleh Yanti dan Sukotjo (2016) menunjukkan bahwa citra merek dan kesadaran merek berpengaruh positif dan signifikan terhadap keputusan pembelian. Hal tersebut menunjukkan adanya keterkaitan antara citra merek dan kesadaran merek. Semakin baik citra yang digambarkan atas suatu merek, maka merek tersebut semakin menarik bagi masyarakat, sehingga semakin tinggi tingkat kesadaran masyarakat terhadap merek tersebut.

$\mathrm{H}_{3}$ : Citra merek berpengaruh positif dan signifikan terhadap kesadaran merek facial foam Pond's di SMK Al-Makmur Ciganjur, Jakarta Selatan.

\section{METODE PENELITIAN}

\section{Sumber dan Jenis Data}

Jenis data yang digunakan dalam penelitian adalah data primer dan cross-section yang bersumber dari hasil penyebaran kuesioner kepada responden.

\section{Populasi dan Sampel}

Populasi penelitian ini terdiri dari siswa-siswi dan karyawan di SMK Al-Makmur Ciganjur, Jakarta Selatan yang menggunakan facial foam Pond's. Penentuan jumlah sampel dilakukan dengan menggunakan rumus Anderson, et al. (2011:364), yaitu sebagai berikut.

$$
\mathrm{n}=\frac{\left(\mathrm{Z}_{\mathrm{a} / 2}\right)^{2} \mathrm{P} *(1-\mathrm{P})}{\mathrm{E}^{2}}
$$

Keterangan:

$\mathrm{Z}_{\mathrm{a} / 2}=\mathrm{Z}$ tabel dengan tingkat signifikansi tertentu

$\mathrm{P} \quad=$ Proporsi populasi

$\mathrm{E}^{2}=$ Tingkat kesalahan yang dapat ditolerir (dinyatakan dalam \%) yaitu $10 \%$.

Berdasarkan rumus tersebut, sampel penelitian ini terdiri dari 100 responden. 


\section{Definisi Operasional Variabel}

Berikut ini merupakan definisi operasional dari variabel yang digunakan dalam penelitian ini.

Tabel 2. Definisi Operasional Variabel

\begin{tabular}{|c|c|c|c|}
\hline No & $\begin{array}{l}\text { Variabel } \\
\text { Penelitian }\end{array}$ & Deskripsi & Indikator \\
\hline 1 & $\begin{array}{l}\text { Celebrity } \\
\text { Endorser }\end{array}$ & $\begin{array}{l}\text { Celebrity endorser adalah suatu } \\
\text { metode promosi yang melibatkan } \\
\text { selebriti untuk menarik minat beli } \\
\text { konsumen. }\end{array}$ & $\begin{array}{l}\text { 1. Attractiveness (daya tarik } \\
\text { fisik) } \\
\text { 2. Trustworthiness (dapat } \\
\text { dipercaya) } \\
\text { 3. Expertise (keahlian) }\end{array}$ \\
\hline 2 & Tagline & $\begin{array}{l}\text { Tagline adalah bagian dari iklan atas } \\
\text { suatu merek yang dibuat sedemikian } \\
\text { rupa agar merek tersebut mudah } \\
\text { diingat dan diminati oleh konsumen. }\end{array}$ & $\begin{array}{l}\text { 1. Familiarity } \\
\text { 2. Differentiation } \\
\text { 3. Message of value }\end{array}$ \\
\hline 3 & Citra Merek & $\begin{array}{l}\text { Citra merek adalah gambaran atas } \\
\text { suatu merek di benak konsumen. }\end{array}$ & $\begin{array}{l}\text { 1. Citra pembuat (corporate } \\
\text { image) } \\
\text { 2. } \begin{array}{l}\text { Citra pemakai (user } \\
\text { image) }\end{array} \\
\text { 3. } \begin{array}{l}\text { Citra produk (product } \\
\text { image) }\end{array}\end{array}$ \\
\hline 4 & $\begin{array}{l}\text { Kesadaran } \\
\text { Merek }\end{array}$ & $\begin{array}{l}\text { Tingkat kemampuan suatu merek } \\
\text { untuk diingat dan dikenali oleh } \\
\text { konsumen. }\end{array}$ & $\begin{array}{ll}\text { 1. } & \text { Recall (mengingat } \\
\text { kembali) } \\
\text { 2. Recognition (mengenali) } \\
\text { 3. Purchase (pembelian) } \\
\text { 4. }\end{array}$ \\
\hline
\end{tabular}

Metode Analisis

Penelitian ini menggunakan metode analisis regresi linear berganda untuk menganalisis pengaruh celebrity endorser, tagline dan citra merek terhadap kesadaran merek

\section{HASIL PENELITIAN DAN PEMBAHASAN}

\section{Hasil Uji Instrumen}

\section{Hasil Uji Validitas}

Berdasarkan hasil uji validitas, semua butir pernyataan dari setiap variabel bersifat valid karena memiliki $r_{\text {hitung }}$ yang lebih besar daripada $r_{\text {tabel }}$ sebesar 0,194. 


\section{Hasil Uji Reliabilitas}

Tabel 3. Hasil Uji Reliabilitas

\begin{tabular}{|l|c|c|c|}
\hline \multicolumn{1}{|c|}{ Variabel } & $\begin{array}{c}\text { Cronbach's } \\
\text { Alpha }\end{array}$ & $\begin{array}{c}\text { Batas Cronbach's } \\
\text { Alpha }\end{array}$ & Keterangan \\
\hline Celebrity Endorser & 0.664 & 0,60 & Reliabel \\
\hline Tagline & 0.736 & 0,60 & Reliabel \\
\hline Citra Merek & 0.667 & 0,60 & Reliabel \\
\hline Kesadaran Merek & 0.689 & 0,60 & Reliabel \\
\hline
\end{tabular}

(Sumber: Data diolah, 2016)

Berdasarkan tabel di atas, setiap variabel mempunyai nilai cronbach's alpha di atas 0,60, sehingga semua konsep pengukur masing-masing variabel dari kuesioner bersifat reliabel.

\section{Hasil Uji Asumsi Klasik}

\section{Hasil Uji Normalitas}

Tabel 4. Hasil Uji Normalitas

\begin{tabular}{|l|r|}
\hline & Unstandardized Residual \\
\hline Asymp. Sig. (2-tailed) & 0.532 \\
\hline
\end{tabular}

(Sumber: Data diolah, 2016)

Berdasarkan tabel di atas, diperoleh asymp. sig (2-tailed) sebesar 0,532 yang lebih besar daripada 0,05 , sehingga data berdistribusi normal.

\section{Hasil Uji Multikolinearitas}

Tabel 5. Hasil Uji Multikolinearitas

\begin{tabular}{|l|r|c|}
\hline \multirow{2}{*}{ Model } & \multicolumn{2}{|c|}{ Collinearity Statistics } \\
\cline { 2 - 3 } & Tolerance & \multicolumn{1}{c|}{ VIF } \\
\hline (Constant) & & \\
Celebrity Endorser & 0.298 & 3.357 \\
Tagline & 0.510 & 1.959 \\
Citra Merek & 0.363 & 2.754 \\
\hline
\end{tabular}

(Sumber: Data diolah, 2016)

Berdasarkan tabel di atas, dapat diketahui bahwa setiap variabel mempunyai nilai tolerance $>0,1$ dan VIF $<10$, sehingga tidak terjadi multikolinearitas dalam model regresi ini. 


\section{Hasil Uji Heteroskedastisitas}

Dalam penelitian ini, uji heteroskedastisitas dilakukan dengan menggunakan menggunakan Spearman's Rho.

Tabel 6. Hasil Uji Heteroskedastisitas

\begin{tabular}{|l|r|}
\hline \multicolumn{1}{|c|}{ Variabel } & $\begin{array}{c}\text { Sig. 2-Tailed of } \\
\text { Unstandardized } \\
\text { Residual }\end{array}$ \\
\hline Celebrity Endorser & 0,973 \\
\hline Tagline & 0,457 \\
\hline Citra Merek & 0,598 \\
\hline
\end{tabular}

(Sumber: Data diolah, 2016)

Berdasarkan tabel di atas, setiap variabel memiliki nilai signifikansi yang lebih besar daripada 0,05 , sehingga tidak terjadi heteroskedastisitas dalam model regresi ini.

\section{Uji Autokorelasi}

Berdasarkan hasil uji autokorelasi, diketahui besarnya nilai DW adalah 1,996. Dengan jumlah variabel bebas sebanyak $3(\mathrm{k}=3)$ dan jumlah sampel sebanyak $100(\mathrm{n}=100)$, diperoleh nilai $\mathrm{dL}=1,613$ dan $\mathrm{dU}=1,736$. Hal tersebut menunjukkan bahwa model yang digunakan dalam penelitian ini memenuhi kriteria $\mathrm{dU}<\mathrm{DW}<4$-dU $(1,736<1,996<2,264)$, sehingga tidak terdapat autokorelasi dalam model regresi ini.

\section{Analisis Regresi Linear Berganda}

Tabel 7. Hasil Uji Regresi Linear Berganda

\begin{tabular}{|l|r|r|r|r|r|}
\hline \multirow{2}{*}{ Model } & \multicolumn{2}{|c|}{$\begin{array}{c}\text { Unstandardized } \\
\text { Coefficients }\end{array}$} & $\begin{array}{c}\text { Standardized } \\
\text { Coefficients }\end{array}$ & \multirow{2}{*}{ T } & \multirow{2}{*}{ Sig. } \\
\cline { 2 - 5 } & B & \multicolumn{1}{c|}{$\begin{array}{c}\text { Std. } \\
\text { Error }\end{array}$} & \multicolumn{1}{|c|}{ Beta } & & \\
\hline (Constant) & 1.012 & 0.629 & & 1.608 & 0.111 \\
Celebrity Endorser & 0.165 & 0.078 & 0.176 & 2.124 & 0.036 \\
Tagline & 0.611 & 0.059 & 0.654 & 10.339 & 0.000 \\
Citra Merek & 0.155 & 0.076 & 0.152 & 2.031 & 0.045 \\
\hline
\end{tabular}

(Sumber: Data diolah, 2016)

Berdasarkan nilai unstandardized coefficient pada tabel di atas, persamaan regresi linear berganda dalam penelitian ini adalah sebagai berikut.

$$
Y=1,012+0,165 X_{1}+0,611 X_{2}+0,155 X_{3}
$$


Keterangan:

$$
\begin{aligned}
& \mathrm{Y}=\text { Kesadaran merek } \\
& \mathrm{X}_{1}=\text { Celebrity endorser } \\
& \mathrm{X}_{2}=\text { Tagline } \\
& \mathrm{X}_{3}=\text { Citra merek }
\end{aligned}
$$

\section{Uji Kelayakan Model}

\section{Uji F}

\section{Tabel 8. Hasil Uji F}

\begin{tabular}{|l|c|c|}
\hline \multicolumn{1}{|c|}{ Model } & F & Sig. \\
\hline $\begin{array}{l}\text { Regression } \\
\text { Residual } \\
\text { Total }\end{array}$ & 131.368 & 0.000 \\
& & \\
\hline
\end{tabular}

(Sumber: Data diolah, 2016)

Berdasarkan tabel di atas, diperoleh tingkat signifikansi sebesar 0,000 yang lebih kecil daripada 0,05, sehingga dapat disimpulkan bahwa celebrity endorser, tagline dan citra merek secara bersama-sama berpengaruh signifikan terhadap kesadaran merek. Artinya, model dalam penelitian ini layak untuk digunakan.

\section{Uji Koefisien Determinasi $\left(\mathbf{R}^{2}\right)$}

Analisis koefisien determinasi $\left(\mathrm{R}^{2}\right)$ digunakan untuk mengetahui seberapa besar persentase variabel terikat yang dapat dijelaskan oleh variabel bebas. Besarnya koefisien determinasi dari model regresi yang digunakan dalam model regresi ini adalah 0,804. Hal tersebut menunjukkan bahwa celebrity endorser, tagline dan citra merek memberikan kontribusi sebesar 80,4\% dalam menjelaskan kesadaran merek, sedangkan 19,6\% sisanya dijelaskan oleh variabel lain yang tidak dianalisis dalam penelitian ini.

\section{Pengujian Hipotesis (Uji T)}

Tabel 9. Hasil Uji T

\begin{tabular}{|l|r|r|c|c|}
\hline \multicolumn{1}{|c|}{ Model } & \multicolumn{1}{|c|}{ T } & Sig. & $\boldsymbol{\alpha}$ & Keterangan \\
\hline Celebrity Endorser & 2.124 & 0.036 & 0.05 & Positif dan signifikan \\
Tagline & 10.339 & 0.000 & 0.05 & Positif dan signifikan \\
Citra Merek & 2.031 & 0.045 & 0.05 & Positif dan signifikan \\
\hline
\end{tabular}

(Sumber: Data diolah, 2016) 
Berdasarkan tabel di atas, setiap variabel mempunyai nilai signifikan yang lebih kecil daripada $\alpha$ sebesar 0,05 , sehingga dapat disimpulkan bahwa celebrity endorser, tagline dan citra merek secara parsial berpengaruh positif dan signifikan terhadap kesadaran merek facial foam Pond's di SMK Al-Makmur Ciganjur, Jakarta Selatan.

\section{Pembahasan}

\section{Pengaruh Celebrity Endorser terhadap Kesadaran Merek}

Hasil penelitian menunjukkan bahwa celebrity endorser berpengaruh positif dan signifikan terhadap kesadaran merek konsumen facial foam Pond's di SMK Al-Makmur Ciganjur, Jakarta Selatan. Hal tersebut menunjukkan bahwa semakin efektif penggunaan celebrity endorser oleh suatu merek, maka semakin tinggi tingkat kesadaran masyarakat terhadap merek tersebut. Hal tersebut dikarenakan celebrity endorser dapat meningkatkan daya tarik terhadap suatu merek, sehingga pada akhirnya akan meningkatkan kesadaran masyarakat terhadap merek tersebut. Hasil penelitian ini sesuai dengan hasil penelitian yang dilakukan oleh Hamid dan Hartati (2013) dan Nugroho dan Mudiantono (2013) yang menunjukan bahwa celebrity endorser berpengaruh positif terhadap kesadaran merek.

\section{Pengaruh Tagline terhadap Kesadaran Merek}

Hasil penelitian menunjukkan bahwa dapat tagline berpengaruh positif dan signifikan terhadap kesadaran merek konsumen facial foam Pond's di SMK Al-Makmur Ciganjur, Jakarta Selatan. Hal tersebut menunjukkan bahwa semakin efektif tagline yang digunakan dalam mempromosikan suatu merek, maka semakin tinggi tingkat kesadaran masyarakat terhadap merek tersebut. Hal tersebut dikarenakan semakin bagus tagline suatu merek, maka semakin mudah konsumen dalam mengerti dan memahami suatu merek, sehingga semakin tinggi daya tarik dan kesadaran masyarakat terhadap merek tersebut. Hasil penelitian sesuai dengan hasil penelitian yang dilakukan oleh Abiromo (2014) yang menunjukkan bahwa tagline bepengaruh positif dan signifikan terhadap kesadaran merek.

\section{Pengaruh Citra Merek terhadap Kesadaran Merek}

Hasil penelitian menunjukkan bahwa citra merek berpengaruh positif dan signifikan terhadap kesadaran merek konsumen facial foam Pond's di SMK Al-Makmur Ciganjur, Jakarta Selatan. Hal tersebut menunjukkan bahwa semakin baik citra dari suatu merek, maka semakin tinggi tingkat kesadaran masyarakat terhadap merek tersebut. Hal tersebut dikarenakan semakin baik citra yang digambarkan atas suatu merek, maka merek tersebut 
semakin menarik bagi masyarakat, sehingga semakin tinggi tingkat kesadaran masyarakat terhadap merek tersebut.

\section{KESIMPULAN DAN SARAN}

\section{Kesimpulan}

Berdasarkan hasil penelitian, dapat disimpulkan bahwa celebrity endorser, tagline, dan citra merek secara parsial mempunyai pengaruh positif dan signifikan terhadap kesadaran merek konsumen facial foam Pond's di SMK Al-Makmur Ciganjur, Jakarta Selatan.

\section{Saran}

Berdasarkan hasil penelitian dan kesimpulan yang telah dikemukakan sebelumnya, perusahaan perlu lebih selektif dalam memilih selebriti yang akan menjadi celebrity endorser dari produk yang diproduksi dan dijualnya. Selain itu, perusahaan juga perlu lebih memperhatikan dan meningkatkan kualitas tagline yang digunakan dalam mempromosikan produknya, serta mempertahankan dan meningkatkan citra mereknya yang positif. Hal tersebut perlu dilakukan untuk meningkatkan tingkat kesadaran masyarakat terhadap merek tersebut.

\section{DAFTAR PUSTAKA}

Aaker, D. 1997. Manajemen Ekuitas Merek. Spektrum Mitra Utama. Jakarta.

Abiromo, B. 2014. Pengaruh Tagline dan Brand Ambassador terhadap Brand Awareness Produk Perdana Simpati: Studi Kasus pada Mahasiswa Fakultas Ekonomi Universitas Negeri Yogyakarta. Skripsi. Program Studi Manajemen Universitas Negeri Yogyakarta. Yogyakarta.

Bramantya, Y.B. dan M. Jatra. 2016. Pengaruh Celebrity Endorser dan Brand Image terhadap Keputusan Pembelian Yamaha Jupiter MX di Kota Denpasar. E-Jurnal Manajemen Universitas Udayana. 5 (3): 1769-1771.

Durianto, D. dan L.J. Budiman. 2004. Brand Equity Ten. Gramedia Pustaka Utama. Jakarta

Hamid, F.Z. dan T. Hartati. 2013. Pengaruh Penggunaan Celebrity Endorser dan Jingle dalam Iklan Televisi Mentari (Indosat) terhadap Brand Awareness pada Karyawan di Lingkungan Beji Depok. Epigram. 10 (2): 80-88.

Keller. K.L. 2003. Strategic Brand Management: Building, Measuring, And Managing Brand Equity. Second Edition. Pearson Prentice Hal. New Jersey

Kotler, P. dan K.L. Keller. 2009. Marketing Management. $13^{\text {th }}$ Edition. Pearson Education. Terjemahan B. Sabran. Manajemen Pemasaran. Edisi 13. Jilid 1. Erlangga. Jakarta. 
Nugroho, S.A dan Mudiantono. 2013. Analisis Pengaruh Daya Tarik Iklan dan Kekuatan Celebrity Endorser terhadap Brand Awareness dan Dampaknya terhadap Brand Attitude Handphone Nokia: Studi Kasus pada Mahasiswa dan Mahasiswi Fakultas Ekonomika dan Bisnis Universitas Diponegoro Semarang. Diponegoro Journal of Management. 2(3): 1-11.

Peter, J. P. dan J.C. Olson. 2013. Consumer Behavior and Marketing Strategy. 7th edition. McGraw Hill. New York. Perilaku Konsumen dan Strategi Pemasaran. Jilid 2. Edisi 7. Salemba Empat. Jakarta.

Rangkuti, F. 2004. The Power of Brand. PT. Gramedia Pustaka Utama. Jakarta

Shimp. A. 2007. Periklanan Promosi. Edisi 5. Jilid 1 dan 2. Erlangga. Jakarta.

Susanto, A.B. dan H. Wijanarko. 2004. Power Branding: Membangun Merek Unggul dan Organisasi Pendukungnya. Mizan. Bandung.

Yanti, M.O.Z. dan H. Sukotjo. 2016. Pengaruh Kesadaran Merek, Asosiasi Merek dan Brand Image terhadap Keputusan Pembelian Aqua. Jurnal Ilmu dan Riset Manajemen. 5(5): $1-15$. 